\title{
Harmful Gases Wireless Network Monitoring System Design
}

\author{
Racharla Sunitha, Arulananth T.S
}

\begin{abstract}
One web for normal wired and scanning organization in the electrifying, capability of action, empathy and other facet of issue, it describes to Zigbee root, GSM machinery. Now Remote recording terminal is used to detect the area habitat and gas alert to detect site state and absorption state. Control station is worn to hold the head base to attach the mesh of remote observation data, anxiety statistics ship to receiver by GSM module monitoring terminal. In inclusion, across the periodical seaport shift information to a computer detector slave, to reach the position from every remote terminal data perusal, administration. Final reaction displays is proficient of extended-period fixed, valid behavior with low power utilization, unfailingly connected, casing a broad zone edge.
\end{abstract}

Keywords: Amino acids, antigenicity, normalization and Protein modeling.

\section{INTRODUCTION}

In the synthetically, fossil fuel and another construction action, injurious seep gas frequently fall, well organized and faithful verity of data assemblage, transferrable and showing system possess suit the pivot of academic abstain different countries. L. Chen suggest ZIGBEE-based radio set detector scheme, carrying out of gas property finding, appalling, but non for dissection and keeping. Chang jiang Li establish build on ZIGBEE technology, the favour of tuner sensor scheme to explain the network opertions and ZIGBEE networking edifice, but didn't advance, utilize network transmission etiquettes. Hsin-Mu Tsai usage technology UV burning of fire security examination, manage single node supplication, without a network, we can't achieve real-time screening. This designs GSM network technologies based on ZIGBEE gas monitoring system that merges low-rate ZIGBEE technology, cheap cost, moderate power expenditure and GSM network coverage, cheap price advantage, the ability to put the terminal data sync to monitoring server, and fitting transmission of the alarm information to pertinent people in impose of advancement of high actual merit.

\section{EXISTING SYSTEM}

In the arrangement based on wireless sensor arrangement carbon dioxide (CO2) absorption ecology arrangement is developed in allusion of gas arising ecology claim for $\mathrm{CO} 2$ abduction and storage. The sensors arrangement of $\mathrm{CO} 2$,

Revised Version Manuscript Received on 10 September, 2019.

Racharla Sunitha, PG student, Department of Electronics and Communication Engineering, MLR Institute of Technology, Hyderabad -43, Telangana, India.

Arulananth T.S, Professor, Department of Electronics and Communication Engineering, MLR Institute of Technology, Hyderabad -43, Telangana, India. temperature, humidity, and ablaze acuteness are acclimated to aggregate abstracts and the GPS receiver bore is adopted to aggregate area and abstracts information. The online ecology Web GIS audiences are developed application a PHP programming. But limitation of this arrangement it uses internet for monitoring. Which agency it should accept 24/7 internet connection. This Arrangement alone raises an anxiety and don't performs any activity to anticipate or abate any the damage.

\section{Disadvantages of existing method}

- No connected monitoring

- Wired gas apprehension system

- Costly

- More adeptness consumption

\section{PROPOSED METHODOLOGY}

Entire environment the capital based on various details, labeled accepting limited extreme details; additionally forward abstracts closed lengthwise utensil; if free a crisis anxiety stuff, through GSM bore to forward argument letters to adaptable buzz utilizes to attach to controlling. The present arrangement deals with the misgiving and blockage of the gas arising as clear in. The gas sensor and arm microcontroller are used. Hence the gas sensor continuously detects flammable and LPG gas. If absorption of the gas in air is above the set then, it turns on the broadcast and gives and arresting to the microcontroller to turns on the buzzer, sprinkler etc. and to the GSM module. This manual is done by application RS232. Again this bore sends the SMS to the defined numbers which are berth into the system.

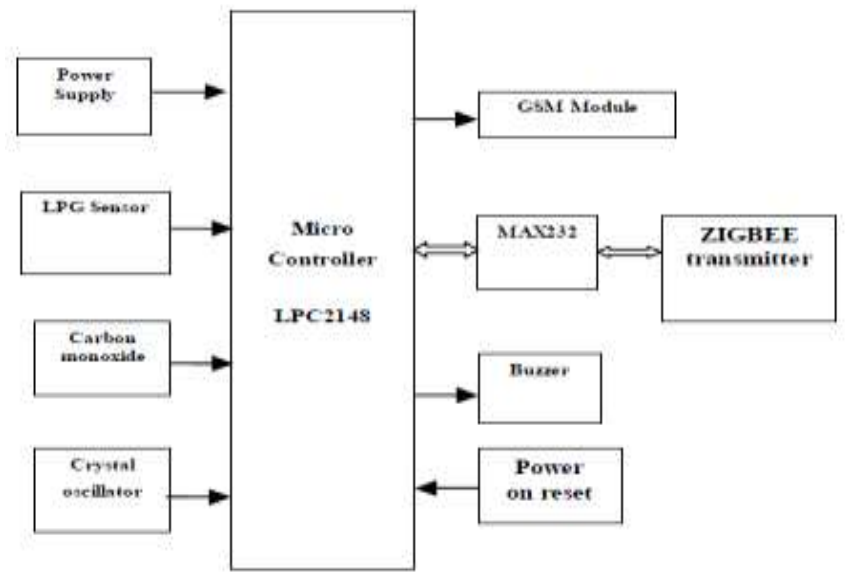

Fig.1 Design of Transmitter Section

Published By: Blue Eyes Intelligence Engineering \& Sciences Publication 


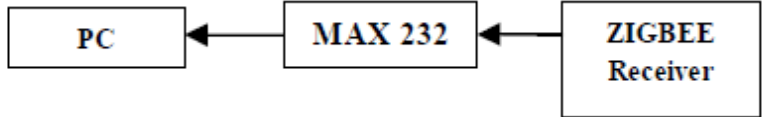

Fig.2 Design of Receiver Section

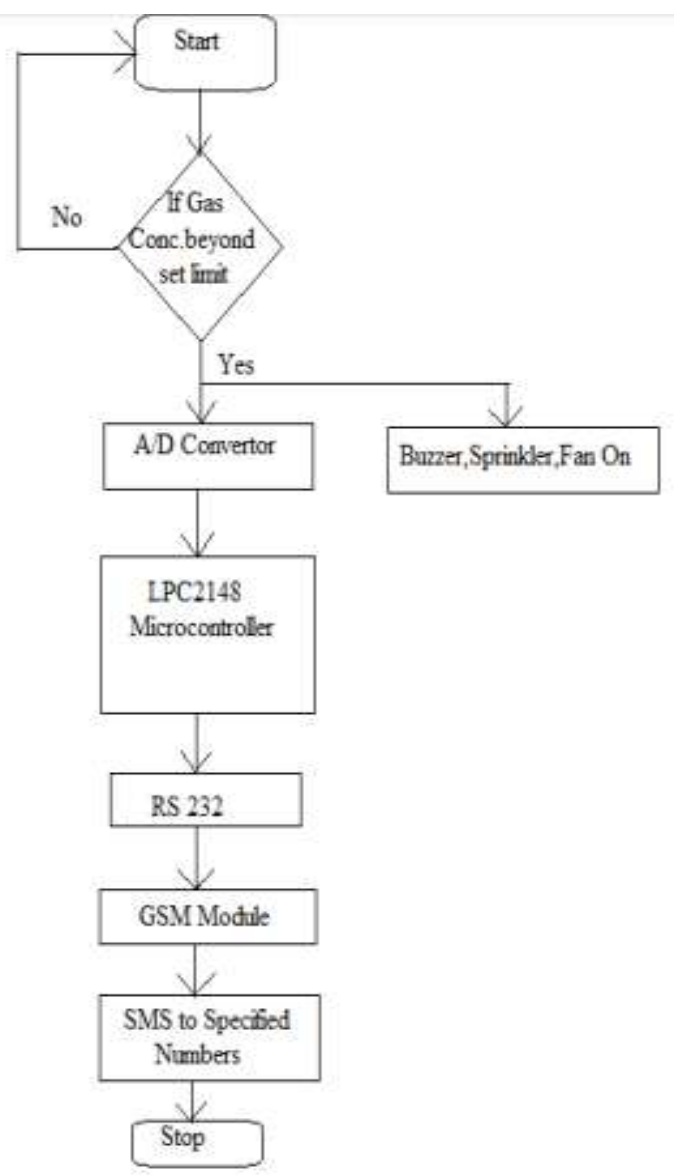

Fig.3 Flowchart of gas monitoring systems

\section{Power supply:}

The power supply is concerted to modify full voltage AC mains piezo effect to fit down voltage pump for shunt and imperfect downwards into a sequence of steps to work a special isometric. A D.C power supply which hold ending voltage unvarying disregarding of A.C mains wave or load deviations is called "Modulated D.C Power Supply"

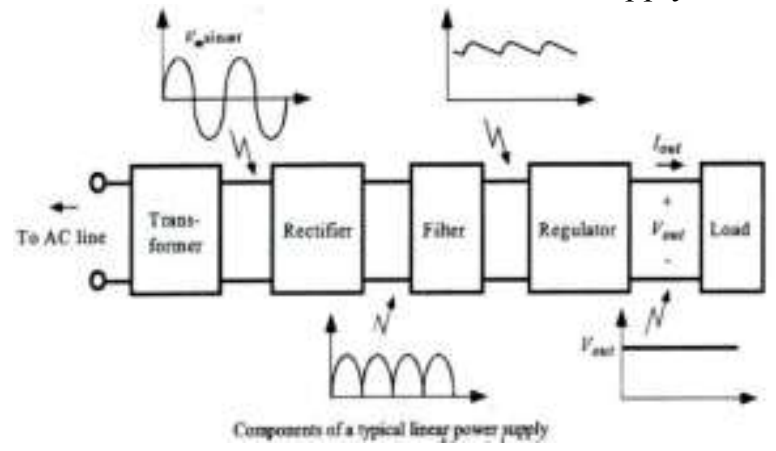

Fig.4 Block diagram of Power supply

\subsection{LPG Sensor:}

A gas photocell finds the inherence of gases in section, off times every point of a bio safety maze played to sight a gas get out and surface along manage system computing can be mechanically layoff, sound an alarm to identity in area where unwrap is passing, delivering them the opening to depart. The procedure of differentiating prospect dangerous gas exposed. Such sensors commonly share a hearable tone to person when a unsafely gas detected. Communal sensors carry unseeable factor, supersonic and semiconductor sensing element. Newly, infrared picturing sensors have come into avail used for a wide board of usage.

\subsection{MAX 232.}

MAX232 converts from RS232 voltage levels to TTL voltage levels, and contrariwise. One positivity of nick is that it shares a $+5 \mathrm{~V}$ power root age which, identifiably beginning voltage for the 8051 .

\subsection{GSM:}

An embedded system is a particular-purpose system in which the computer is fulfill concentrated by sacrificed to deals world System for Mobile Communication is set of ETSI providing the base for digital cell-like work. The baseline is used in approx. Eighty five domains in the world having many regions as Europe, Japan and Australia.

\subsection{Zigbee Technology:}

A new wireless profession conducted by the IEEE 802.15.4 Private Area scheme gauge. Only wireless standards-based technology that reference alone wants of remote spy and control, receptive engineering. Sensors and controls don't be full bandwidth but they do need low potency, very low radiation ingestion for long artillery occupies large device matrix.

\section{RESULTS AND DISCUSSUIONS}

The arrangement is developed and activated on simulation. The arrangement simulation is done by application the Proteus software 8.0.and it is activated on simulation data. It is empiric that, the arrangement works actual acceptable for set beginning and accord the achievement audio beheld signal. 


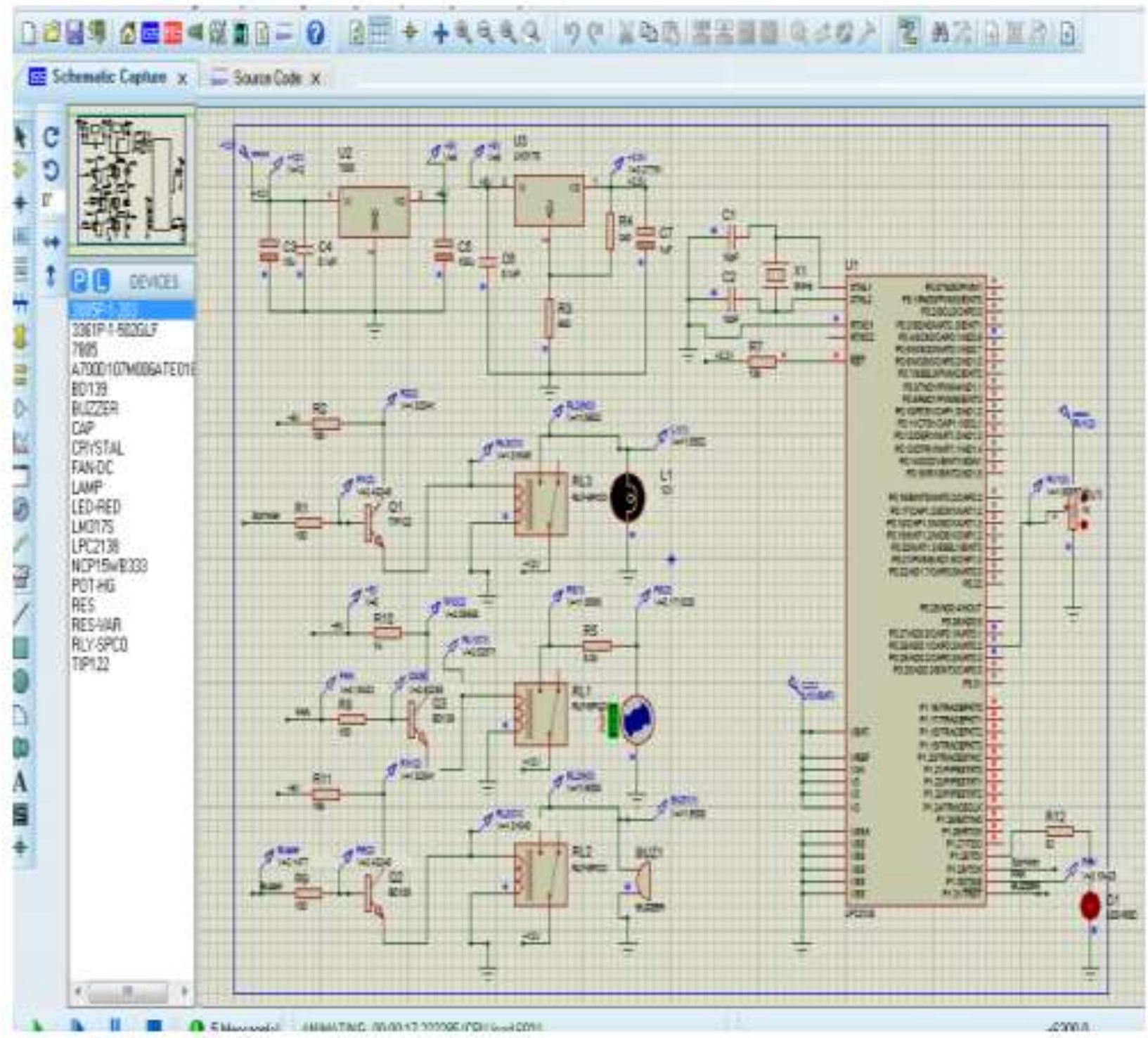

Fig.5 Simulation Output

There is an ecology arrangement is mostly the capital stage, two limited terminal, an adaptable buzz, date apparatus.

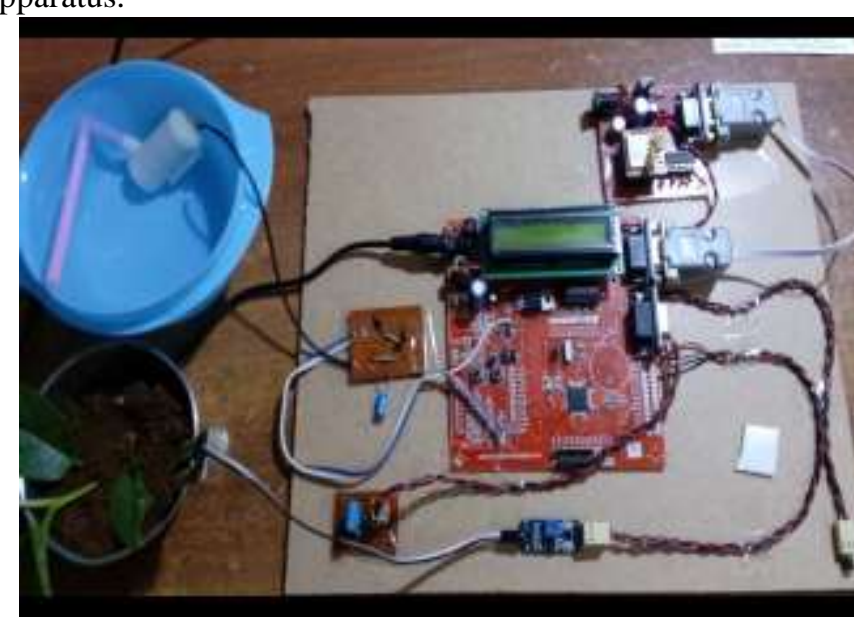

Fig.6 Experimental hardware setup

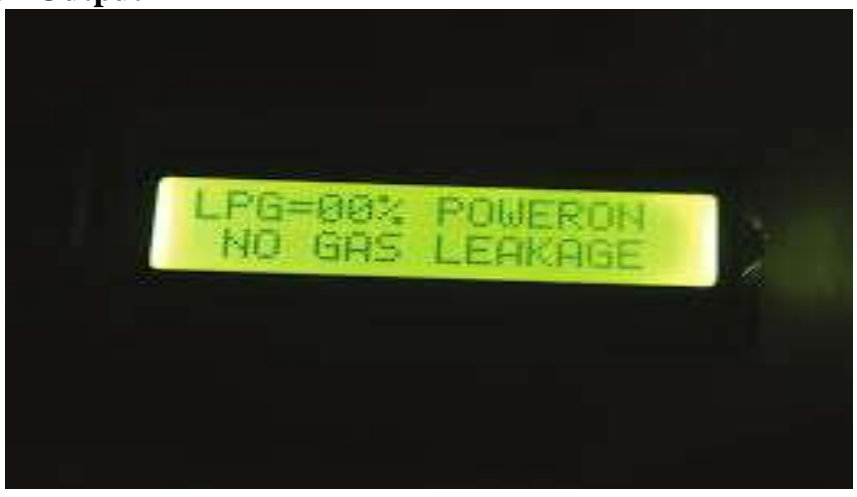

Fig.7 Displaying the data on LCD

Previously proving the GSM bore into an adaptable adviser careful consecutive anchorage is affiliated to the capital station. There is an ecology arrangement is mainly the capital station, 2 narrow terminal, an adaptable buzz and a date apparatus into.

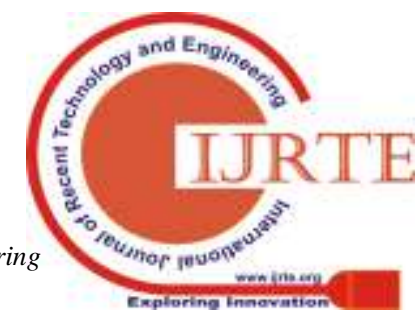




\section{CONCLUSION AND FUTURE SCOPE}

The results show that under the empirical normality, ZigBee wireless sensor network can speedily accepting child node network, data transceiver, manipulate with user through the GSM, the PC real-time exhibit of temperature, wetness and property arcs and information.

The proposed fresh access to adviser and ascertain the arising of LPG gas is apish a developed which detects the arising of gas in the air and if it exceeds assurance akin again it activates the buzzer and sends the SMS to the defined numbers by application GSM. Application this user gets active in the chancy and aberrant activity to yield the all-important action. We can obtain the accidents acquired by gas arising with the advice of this system.

\section{REFERENCES}

1. Lei Chen, Shuang Yang. Based on ZigBee Wireless Sensor Network the Monitoring System Design for Chemical Production Process Toxic and Harmful Gas. Mechatronics, Control and Electronic Engineering (CMCE), vol.4, pp.255-258, 2010.

2. Chang jiang Li, Yufen Wang. The Application Research of Wireless Sensor Network Based on ZigBee, Multimedia and Information Technology (MMIT), pp.89-92, 2010.

3. Cheong, P., Ka-Fai Chang, Ying-Hoi Lai, Sut-Kam Ho, Iam-Keong Sou $\square$ Kam-Weng Tam. A ZigBee-Based Wireless Sensor Network Node for Ultraviolet Detection of Flame. Industrial Electronics, Vol58 (11), pp.5271-5277, 2011.

4. Tae-seok Lee, Yuan Yang, "A SMS Based Ubiquitous Home Care System”, University of Korea, 2005

5. American Industrial Hygiene Association, Air Pollution Manual, Brawn-Brumfield, Inc., 1960, Vols, I \& II.

6. K. A Othman, N Li, E. H Abdullah, N Hamzah, "Haze Monitoring System in City of Kuala Lumpur using Zigbee Wireless Technology Implementation", WCE 2013

7. V. N. Bashkin (2003). "Environmental Chemistry: Asian Lessons", pp 115-11. 